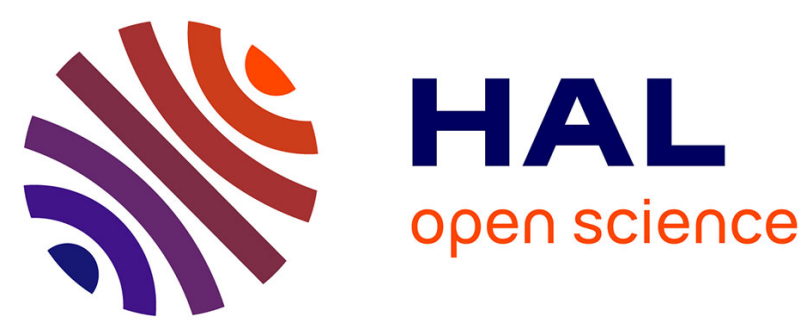

\title{
Apgar Scores Reported in Personal Child Health Records: Validity for Epidemiological Studies?
}

Penelope Troude, Laurence Foix-L'Hélias, Anne-Marie Raison-Boulley, Christine Castel, Jean Bouyer, Elise de La Rochebrochard

\section{- To cite this version:}

Penelope Troude, Laurence Foix-L'Hélias, Anne-Marie Raison-Boulley, Christine Castel, Jean Bouyer, et al.. Apgar Scores Reported in Personal Child Health Records: Validity for Epidemiological Studies?. Journal of Paediatrics and Child Health, 2008, 44 (11), pp.665-669. 10.1111/j.14401754.2008.01379.x . hal-02197297

\section{HAL Id: hal-02197297 \\ https://hal.science/hal-02197297}

Submitted on 30 Jul 2019

HAL is a multi-disciplinary open access archive for the deposit and dissemination of scientific research documents, whether they are published or not. The documents may come from teaching and research institutions in France or abroad, or from public or private research centers.
L'archive ouverte pluridisciplinaire HAL, est destinée au dépôt et à la diffusion de documents scientifiques de niveau recherche, publiés ou non, émanant des établissements d'enseignement et de recherche français ou étrangers, des laboratoires publics ou privés. 


\title{
Apgar Scores Reported in Personal Child Health Records:
}

\section{Validity for Epidemiological Studies?}

\author{
Pénélope Troude a,b,c , Laurence Foix L’Héliass ${ }^{\mathrm{d} \text { e, f }}$, Anne-Marie Raison-Boulley, ${ }^{\mathrm{g}}$, \\ Christine Castel $^{\mathrm{g}}$, Jean Bouyer ${ }^{\mathrm{a}, \mathrm{b}, \mathrm{c}}$ and Elise de La Rochebrochard ${ }^{\mathrm{a}, \mathrm{b}, \mathrm{c}}$
}

${ }^{a}$ Ined, F-94276 Le Kremlin-Bicêtre, France

${ }^{\mathrm{b}}$ Inserm U822, F-94276 Le Kremlin-Bicêtre, France

c Université Paris-Sud, Faculté de Médecine Paris-Sud, F-94276 Le Kremlin-Bicêtre, France

d Inserm U149, F-94807 Villejuif, France

${ }^{\mathrm{e}}$ Université Pierre et Marie Curie-Paris 6, F-75252 Paris, France

f Service de Pédiatrie et Réanimation Néonatales, GHU Sud, Hôpital Universitaire Antoine Beclère, F-92141 Clamart, France

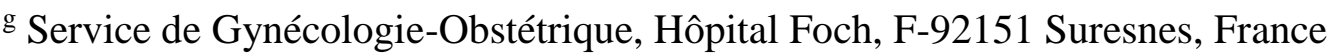

Correspondence to:

Elise de La Rochebrochard

Unité U822

82 rue du Général Leclerc

94276 Le Kremlin-Bicêtre, France

Tel: +33145212333

Fax: +33145212075

E-mail: roche@ined.fr 


\begin{abstract}
Aim: In epidemiological studies on children, information in the neonatal period that might affect children's long-term health could be extracted from the personal child health record (PCHR), since the booklet exists in most countries. We aimed to assess, in individual children, the validity of Apgar scores reported in the PCHR using maternity medical records as the gold standard.
\end{abstract}

Methods: In two French hospitals, 435 women who had a child in January 2006 were recruited and 90 percent filled in a postal questionnaire 6 weeks after delivery, copying neonatal information (including Apgar scores) from the PCHR. This information was compared with data independently recorded at birth by physicians in maternity medical records.

Results: We found that the proportion of missing Apgar scores in the PCHR was higher when scores in the medical records were lower. Moreover, Apgar scores reported in the PCHR were overestimated when scores in the medical records were low. Using medical records as the gold standard, specificity for PHCR-reported 1-min Apgar score was 100 percent and sensitivity 33 percent. Similar trends were found for the 5-min score. This supports the hypothesis that information considered as "socially sensitive" by physicians may be intentionally altered in PCHRs.

Conclusions: Apgar scores reported in PCHRs may not yield reliable information for epidemiological studies. When the PCHR is the only source of information for the neonatal period in an epidemiological study, it would be preferable to use a composite neonatal indicator rather than the Apgar score.

Key words: Apgar score, infant, newborn, medical records.

Abbreviations: PCHR personal child health record, CI confidence interval. 


\section{Key points:}

1- When Apgar scores in medical records are low, Apgar scores are often missing in the Personal Child Health Record (PCHR) or, when reported, they are overestimated.

2- Overestimation of the Apgar score and the non-random pattern of missing values support the hypothesis that information considered as "socially sensitive" by physicians may be intentionally altered in PCHRs.

3- Apgar scores reported in PCHRs do not yield reliable information for assessing child health at birth in epidemiological studies. 


\section{Introduction}

In studies on child health and development, neonatal factors have to be considered since it has been clearly demonstrated that pregnancy, delivery and events during the first days of life are correlated with future child or even adult health ${ }^{1-3}$. Among child health indicators at birth, the Apgar score has been shown to predict neonatal mortality and neurological development ${ }^{4-8}$. This score evaluates newborns at 1 and 5 minutes after birth on the basis of 5 vital signs (heart rate, respiratory effort, color, muscle tone and responsiveness to stimuli). In most countries, no national neonatal registries exist, and neonatal information must be retrieved from the medical records of the maternity departments. However, data collection from obstetric records is problematic because medical records are dispersed in various hospitals, making data collection very timeconsuming, expensive and sometimes impossible.

The personal child health record (PCHR) could be a promising alternative approach to obtain the neonatal data required for epidemiological studies, since PCHRs containing information on the health of newborns exist in most European countries ${ }^{9}$. In France, the newborn's PCHR is systematically given to his/her family on the day of discharge from the maternity department and is kept by the family at home. It contains information on health status at birth, the child's diseases, vaccinations and growth curves, and also advice for parents and health education pages. Several studies have found a 90 to 100 percent completion rate for birthweight in PCHRs ${ }^{10-12}$. Studying their use for epidemiological purposes, the Millennium Cohort study found that the child's last weight was recorded in 97 percent of PCHRs consulted ${ }^{13}$. Hampshire et al found in the UK that child health surveillance reviews were well recorded in PCHRs ${ }^{14}$. The 
satisfactory completion suggested by these studies indicates that PCHRs are potentially useful for epidemiological studies.

However, this completion rate may be lower for some categories of information. For instance, a British review of 140 PCHRs found that information related to delivery was recorded in only 84 percent ${ }^{11}$ and an Australian study of retention and use of PCHRs found Apgar scores recorded in 86 percent of those examined ${ }^{10}$. Furthermore, a French study has suggested that missing information in PCHRs might not be random: socially sensitive information could be voluntarily omitted ${ }^{15}$. The authors suggested such possible bias with regard to immunodeficiency virus status, genetic diseases, psychological disorders and Apgar scores. Because the PCHR is kept by the family and is often passed on to other persons, particularly in school, it raises the problem of confidentiality. In consequence, accuracy of reporting may be voluntarily compromised by physicians when recording information considered as potentially socially detrimental to the child if disclosed. Such a hypothesis could be termed "intentional data alteration" and requires testing. In particular, it would be of great interest to investigate this hypothesis with regard to Apgar scores, which are an important long-term health predictor ${ }^{5}$ and could be considered as potentially sensitive information since they may be seen as a "label" and are thought to be predictive of the child's development ${ }^{5,7}$.

The aim of this study was to test the "intentional data alteration" hypothesis on Apgar scores in the PCHR in individual children, using maternity medical records as the gold standard. 


\section{Methods}

The study was carried out between January 1 and February 4, 2006, in two hospitals in the Paris region (France). Foch hospital has a level II maternity department (with a neonatal department) and Béclère hospital a level III maternity department (with a neonatal intensive care unit). The study received approval from the French Data Protection Authority (CNIL) in September 2005 (authorization number 05-1335). During the inclusion period, 484 women delivered and within 24 to 48 hours following delivery the majority ( $n=473,98 \%$ ) were asked by pediatricians to participate in the study. Eleven mothers were not asked to participate because they were discharged before they could be seen by the pediatricians. Others $(n=38)$ were excluded because of adverse pregnancy outcome (fetal death in utero or pregnancy termination) or poor condition of the newborn $(n=12)$, mother's transfer to an intensive care unit for more than 48 hours $(n=4)$, age under legal majority $(n=2)$, difficulties with the French language $(n=16)$, or major psychological disorders $(n=4)$. Of the 435 remaining women, 422 agreed to take part (participation rate 97\%).

We first collected from medical records information on maternal health, pregnancy and the child's health during the first days of life at the maternity hospital.

Six weeks after delivery, mothers were asked to fill in a postal questionnaire. A total of 392 mothers responded to the questionnaire (response rate 93\%), which included items on parents' sociodemographic characteristics, antenatal and obstetric complications, delivery, child's health at birth and conditions of return home. Mothers were asked to copy data from the PCHR concerning gestational age, birthweight, birth size, cranial circumference at birth and Apgar scores at 1 and 5 minutes. The relevant 
pages of the PCHR were indicated in the postal questionnaire to help mothers find the information.

In order to investigate specifically the "intentional data alteration" hypothesis on Apgar scores, we controlled for possible general altered data in PCHRs by selecting mothers who had accurately reported, in the questionnaire, neonatal information that was not socially sensitive (birthweight, birth size and cranial circumference at birth). Reporting of this neonatal information was considered as accurate if the mother's reports of birthweight, birth size and cranial circumference at birth were within 2 percent of the values noted in medical records (which represents a maximum variation of $50 \mathrm{~g}$ for birthweight, $5 \mathrm{~mm}$ for birth size and $2 \mathrm{~mm}$ for cranial circumference at birth). In multiple pregnancies we included only the firstborn of the twins or triplets. We excluded 5 mothers because the 1-min or 5-min Apgar score was missing in the medical records. Finally, analyses were conducted among 331 mother-child dyads.

To assess the validity of Apgar scores, information from medical records was considered as the gold standard. Sensitivity and specificity of PCHR-reported Apgar scores were calculated using a cut-off of $7(<7$ or $\geq 7)$ since a score from 7 to 10 indicates a child in good condition ${ }^{16,17}$. Percentages were compared using the chisquare test or Fisher's exact test. All statistical analyses were performed using Stata/SE 9.0 (Stata Press, College Station, TX, USA). 


\section{Results}

The characteristics of the study population are described in Table 1. The first part of the table summarizes the child's characteristics at birth. Of these 331 children, 7.6 percent were preterm and 12.7 percent were transferred to a neonatology unit. The second part of Table 1 describes the sociodemographic characteristics of mothers. Most of the mothers were French (others were mainly natives of Africa or Europe) and lived as a couple, their mean age was 32 years and 77 percent had an educational level higher than the baccalaureat (high school diploma).

The 1-min Apgar score was missing in 7.9 percent $(n=26)$ of PCHRs and the 5-min score in 6.0 percent $(n=20)$. When the 1-min Apgar score noted in the medical records was $\geq 7,5.0$ percent $(n=15)$ of 1-min Apgar scores were missing in the PCHR versus 37.9 percent $(\mathrm{n}=11)$ when the Apgar score in the medical records was $<7(\mathrm{p}<0.001)$. Similar results were observed for 5-min Apgar scores, which were missing in 5.5 percent $(n=18)$ of PCHRs when the score noted in the medical records was $\geq 7$ and in 66.7 percent $(n=2)$ of PCHRs when the score was $<7$ in the medical records $(\mathrm{p}=0.01)$.

Table 2 shows the agreement between medical records and PCHRs for the 1-min Apgar score when this score was noted in the PCHR $(n=305)$. Using medical records as the gold standard, specificity for PHCR-reported 1-min Apgar score $<7$ was 100\% (95\% CI $[98.7 \%, 100 \%])$ and sensitivity $33.3 \%$ [13.3\%, 59.1\%]. When comparing the exact value of the Apgar score (and not only by classes $<7 / \geq 7$ ), the 1-min Apgar scores were wrongly reported in 81 PCHRs: they were all higher in the PCHR than in medical records (on average, 1.9 point higher in the PHCR).

Finally, when considering all the 1-min Apgar scores noted in the medical records $<7(\mathrm{n}=29)$, we observed that $37.9 \%$ were missing, $41.4 \%$ were reported as $\geq 7$ in the 
PCHR and only $20.7 \%$ were reported as $<7$ in the PCHR. When considering all the 1min Apgar scores noted in the medical records $\geq 7(n=302)$, we observed that $5.0 \%$ were missing, $0.0 \%$ were reported as $<7$ in the PCHR and $95.0 \%$ were reported as $\geq 7$ in the PCHR.

Of the 28 wrongly reported 5-min scores in PCHRs, the same tendency to overestimation as for 1-min scores was observed: only one 5-min Apgar score was higher than in medical records. Sample size for low 5-min Apgar scores was too small to estimate sensitivity and specificity analyses with a cut-off of 7 , but with a 5-min score cutoff of $9(<9$ or $\geq 9)$, results were similar to those for 1-min Apgar scores: specificity was $100 \%[98.8 \%, 100 \%]$ and sensitivity $27.3 \%[6.0 \%, 61.0 \%]$. 


\section{Discussion}

Our results supported the hypothesis that the Apgar scores reported in PCHRs may provide altered information, as low scores are more likely to be misreported. Firstly, we should not be reassured by the fairly low rate of missing scores (6-8 percent) since they were not missing at random (more missing values in PCHRs when Apgar scores were low in medical records). Secondly, Apgar scores reported in PCHRs were systematically higher than in medical records when the two sources differed. This could induce differential biases. Indeed, when the 1-min score was less than 7 in the PCHR, we could be almost certain that it was the same in medical records (positive predictive value $100 \%$ ); on the contrary, only 20.7 percent of the lowest 1-min Apgar scores in the medical records (lower than 7) were correctly reported in the PCHR (because of both missing values and overestimation of the Apgar score reported in the PCHR). When the 1-min Apgar score was reported in the PCHR, it lacked the sensitivity to reflect low scores reported in medical records but its specificity was good.

In our study population, the mothers' educational level was higher than in the general French population ${ }^{18}$. This was mainly due to the recruitment of the participating maternity hospitals. Thus, we cannot rule out an overestimation of the validity of Apgar scores reported from PCHRs by the mothers of higher educational level in our study. However, since our objective was to investigate how Apgar scores were recorded in PCHRs, we did not seek to obtain a representative population of women giving birth. On the contrary, we sought to minimize misreporting by mothers in order to attribute, as far as possible, low validity of Apgar scores to reporting in PCHRs instead of to mothers' copying errors. For the same reason, analysis was restricted to women who accurately reported information other than Apgar scores. 
Previous analysis of PCHRs mostly focused on their use and acceptability and rarely on the validity of the information they contain $10,11,13,14,19-21$. Some studies, showing relatively good completion of PCHRs, suggested that they are potentially useful in epidemiological studies 10-12, 20 . However, these studies did not specifically assess reliability of neonatal information reported in PCHRs in comparison with other sources, and almost none addressed the issue of the Apgar score. When comparing distribution of PCHR Apgar scores with that of scores collected in the French Department for Mother and Infant Welfare, Vincelet et al suggested that Apgar scores could be underreported in PCHRs ${ }^{22}$. However, the implication of these results was limited because the PCHR data was only globally compared with another source, without checking the validity of the PCHR at the individual level. In our study, we were able to compare individual PCHR information to that in the child's medical record, and we found that low Apgar scores were both more often missing and more often wrongly reported in PCHRs when they were low in medical records. This observation supported the hypothesis of "intentional data alteration" of Apgar scores, leading not only to missing values when the information is socially sensitive but also to misreporting (by noting a higher Apgar score than the true score).

Misreporting of low Apgar scores in PCHRs may be explained by the fact that both physicians and parents overestimate the importance of this score as a predictor of a child's health and development. In an American study among 172 health care professionals, Paneth and Fox showed a 10-fold overestimate of the impact of a low 5min Apgar score on handicap risk and concluded that the score's predictive value is largely overestimated by professionals, who in their study were mainly obstetricians, pediatricians and nurses ${ }^{23}$. Other studies found that parents did not properly understand 
the purpose or value of the score, thinking that their child had somehow failed if he or she did not receive a score of 10 , whereas a score higher than 7 is considered as normal 16, 17. It would be interesting to investigate more thoroughly the reasons for misreporting of low Apgar scores in PCHRs, in particular possible overestimation of its predictive value by physicians as well as misrepresentation by parents, in order to increase the quality of this information in the PCHR by better informing physicians and parents as to the purpose of the Apgar score. Moreover, similar research on validity of Apgar scores reported in PCHRs in other hospitals and other countries would be useful to confirm our results.

Our results show that Apgar scores recorded in PCHRs are a biased source of information for epidemiological purposes. So although the Apgar score may be pertinent for assessing the neonatal period 5, 17, 24-26, we suggest that the Apgar scores reported in the PCHR should not be used in epidemiological studies on children's longterm outcome. Instead, they should be replaced by a composite indicator compiled from more accurate information that is less socially sensitive, such as birthweight, gestational age and transfer of the newborn to a neonatology unit, that has been shown to be relevant also for predicting future child health ${ }^{1}$. 


\section{References}

1 Gissler, M., Järvelin M-J., Louhiala P., Rahkonen O. and Hemminki E., Can children's health be predicted by perinatal health?, Int $J$ of Epidemiol, 1999, 28: 276-80.

2 Frontini, M. G., Srinivasan, S. R., Xu, J. and Berenson, G. S., Low birth weight and longitudinal trends of cardiovascular risk factor variables from childhood to adolescence: the bogalusa heart study, BMC Pediatr, 2004, 4: 22.

3 Bergvall, N., Iliadou, A., Johansson, S., de Faire, U., Kramer, M. S., Pawitan, Y., Pedersen, N. L., Lichtenstein, P. and Cnattingius, S., Genetic and Shared Environmental Factors Do Not Confound the Association Between Birth Weight and Hypertension. A Study Among Swedish Twins, Circulation, 2007.

4 Apgar, V., A proposal for a new method of evaluation of the newborn infant, Curr Res Anesth Analg, 1953, 32: 260-7.

5 Casey, B. M., McIntire, D. D. and Leveno, K. J., The continuing value of the Apgar score for the assessment of newborn infants, $N$ Engl J Med, 2001, 344: 467-71.

6 Moster, D., Lie, R. T. and Markestad, T., Joint association of Apgar scores and early neonatal symptoms with minor disabilities at school age, Arch Dis Child Fetal Neonatal Ed, 2002, 86: F16-21.

7 Moster, D., Lie, R. T., Irgens, L. M., Bjerkedal, T. and Markestad, T., The association of Apgar score with subsequent death and cerebral palsy: A population-based study in term infants, J Pediatr, 2001, 138: 798-803.

8 Thorngren-Jerneck, K. and Herbst, A., Perinatal factors associated with cerebral palsy in children born in Sweden, Obstet Gynecol, 2006, 108: 1499-505. 
9 Rollet, C., Le carnet de santé pour les enfants en Europe, Medicina e storia, 2002, 7: $31-55$.

10 Jeffs, D., Nossar, V., Bailey, F., Smith, W. and Chey, T., Retention and use of personal health records: a population-based study, J Paediatr Child Health, 1994, 30: $248-52$.

11 Lakhani, A. D., Avery, A., Gordon, A. and Tait, N., Evaluation of a home based health record booklet, Arch Dis Child, 1984, 59: 1076-81.

12 Chalumeau, M., Information recorded by maternity ward staff in permanent pediatric health records, Arch Pediatr., 2003, 10: 776-80.

13 Walton, S., Bedford, H. and Dezateux, C., Use of personal child health records in the UK: findings from the millennium cohort study, $B M J, 2006,332: 269-70$.

14 Hampshire, A. J., Blair, M. E., Crown, N. S., Avery, A. J. and Williams, E. I., Are child health surveillance reviews just routine examinations of normal children?, Br J Gen Pract, 1999, 49: 981-5.

15 Dommergues, J. P., [Personal child health record: informativity and confidentiality], Arch Pediatr, 2004, 11 Suppl 1: 42s-45s.

16 Letko, M. D., Understanding the Apgar score, J Obstet Gynecol Neonatal Nurs, 1996, 25: 299-303.

17 Montgomery, K. S., Apgar Scores: Examining the Long-term Significance, $J$ Perinat Educ, 2000, 9: 5-9.

18 Blondel, B., Supernant K., Du Mazaubrun C., Bréat G., Enquête périnatale 2003: situation en 2003 et évolution depuis 1998, DGS, 2003.

19 O'Flaherty, S., Jandera, E., Llewellyn, J. and Wall, M., Personal health records: an evaluation, Arch Dis Child, 1987, 62: 1152-5. 
20 Saffin, K. and Macfarlane, A., How well are parent held records kept and completed?, Br J Gen Pract, 1991, 41: 249-51.

21 Emon, A., Howat, P. and Evans, J., Reliability of parent-held child health records, Health Visit, 1995, 68: 322-3.

22 Vincelet, C., Tabone, M. D., Berthier, M., Bonnefoi, M. C., Chevallier, B., Lemaire, J. P. and Dommergues, J. P., [How are personal child health records completed? A multicentric evaluation study], Arch Pediatr, 2003, 10: 403-9.

23 Paneth, N. and Fox, H. E., The relationship of Apgar score to neurologic handicap: a survey of clinicians, Obstet Gynecol, 1983, 61: 547-50.

24 Jepson, H. A., Talashek, M. L. and Tichy, A. M., The Apgar score: evolution, limitations, and scoring guidelines, Birth, 1991, 18: 83-92.

25 Bharti, B. and Bharti, S., A review of the Apgar score indicated that contextualization was required within the contemporary perinatal and neonatal care framework in different settings, J Clin Epidemiol, 2005, 58: 121-9.

26 ACOG Committee Opinion. Number 333, May 2006 (replaces No. 174, July 1996): The Apgar score, Obstet Gynecol, 2006, 107: 1209-12. 
Table 1. Characteristics of the Study Population $(n=331)$

\begin{tabular}{|c|c|c|}
\hline Children's characteristics ${ }^{\text {(a) }}$ & $\mathrm{n}$ & $\%$ \\
\hline $\begin{array}{l}\text { Sex } \\
\text { Boy } \\
\text { Girl }\end{array}$ & $\begin{array}{l}183 \\
148\end{array}$ & $\begin{array}{l}55.3 \\
44.7\end{array}$ \\
\hline $\begin{array}{l}\text { Gestational age } \\
\quad<32 \text { weeks } \\
\quad \geq 32 \text { and }<37 \text { weeks } \\
\quad \geq 37 \text { weeks }\end{array}$ & $\begin{array}{c}2 \\
23 \\
305\end{array}$ & $\begin{array}{c}0.6 \\
7.0 \\
92.4\end{array}$ \\
\hline $\begin{array}{l}\text { Birthweight } \\
\quad<2500 \mathrm{~g} \\
\quad 2500-3499 \mathrm{~g} \\
\quad \geq 3500 \mathrm{~g}\end{array}$ & $\begin{array}{c}23 \\
196 \\
112\end{array}$ & $\begin{array}{c}7.0 \\
59.2 \\
33.8\end{array}$ \\
\hline $\begin{array}{l}\text { Birth length } \\
\quad<50 \mathrm{~cm} \\
\quad \geq 50 \mathrm{~cm}\end{array}$ & $\begin{array}{l}144 \\
187\end{array}$ & $\begin{array}{l}43.5 \\
56.5\end{array}$ \\
\hline $\begin{array}{l}\text { Birth head circumference } \\
\quad \leq 33 \mathrm{~cm} \\
34-35 \mathrm{~cm} \\
\geq 36 \mathrm{~cm}\end{array}$ & $\begin{array}{c}79 \\
162 \\
90\end{array}$ & $\begin{array}{l}23.9 \\
48.9 \\
27.2\end{array}$ \\
\hline $\begin{array}{l}\text { Newborn transferred to neonatology unit } \\
\text { No } \\
\text { Yes }\end{array}$ & $\begin{array}{c}289 \\
42\end{array}$ & $\begin{array}{l}87.3 \\
12.7\end{array}$ \\
\hline $\begin{array}{l}\text { 1-min Apgar score } \\
0-4 \\
5-6 \\
7-9 \\
10\end{array}$ & $\begin{array}{c}12 \\
17 \\
112 \\
190\end{array}$ & $\begin{array}{c}3.6 \\
5.1 \\
33.8 \\
57.4\end{array}$ \\
\hline $\begin{array}{l}\text { 5-min Apgar score } \\
5-7 \\
8-9 \\
10\end{array}$ & $\begin{array}{c}4 \\
38 \\
289\end{array}$ & $\begin{array}{c}1.2 \\
11.5 \\
87.3\end{array}$ \\
\hline Mothers' characteristics ${ }^{(\mathrm{b})}$ & $n$ & $\%$ \\
\hline $\begin{array}{l}\text { Maternal age } \\
\leq 24 \text { years } \\
25-29 \text { years } \\
30-34 \text { years } \\
35-39 \text { years } \\
\geq 40 \text { years }\end{array}$ & $\begin{array}{c}10 \\
79 \\
133 \\
81 \\
25\end{array}$ & $\begin{array}{c}3.0 \\
23.9 \\
40.2 \\
24.5 \\
7.6\end{array}$ \\
\hline $\begin{array}{l}\text { Nationality } \\
\text { French } \\
\text { Others }\end{array}$ & $\begin{array}{c}300 \\
31\end{array}$ & $\begin{array}{c}90.6 \\
9.4\end{array}$ \\
\hline $\begin{array}{l}\text { Educational level } \\
\quad<\text { Baccalaureat (high school diploma) } \\
\geq \text { Baccalaureat (high school diploma) }\end{array}$ & $\begin{array}{c}75 \\
251\end{array}$ & $\begin{array}{l}22.7 \\
75.8\end{array}$ \\
\hline
\end{tabular}




\section{Occupation}

Manager

106

32.0

Intermediate occupation

85

Employee or worker

120

25.7

Unemployed

10

36.3

Living as a couple

Yes

311

3.0

No

20

94.0

(a) Information obtained from medical records

(b) Information obtained through postal questionnaire 
Table 2. Agreement of 1-min Apgar Score between Medical Records and Personal Child Health Records (PCHR) when Score was Recorded in the PCHR $(n=305)$

\begin{tabular}{lcccc}
\hline & & \multicolumn{2}{c}{ l-min Apgar score in medical records } & Total \\
\cline { 2 - 4 } & & $<7$ & $\geq 7$ & $n(\%)$ \\
\hline Reported & $<7$ & $6(\%)$ & $n(\%)$ & $6(2.0)$ \\
in PCHR & $\geq 7$ & $12(66.7)$ & $287(0)$ & $299(98.0)$ \\
\hline Total & $18(100)$ & $287(100)$ & $305(100)$ \\
\hline \multicolumn{4}{c}{ Sensitivity } & $33.3 \%[13.3 \%, 59.1 \%]$ \\
& \multicolumn{4}{c}{ Specificity $100 \%[98.7 \%, 100 \%]$} \\
\hline
\end{tabular}

